\title{
APLICACIÓN DEL ARTÍCULO 68 DEL CÓDIGO PENAL EN CASO DE SEMIIMPUTABILIDAD Y MULTIRREINCIDENCIA
}

\author{
Mario Sánchez Dafauce \\ Profesor Visitante de Derecho Penal. Universidad Carlos III de Madrid.
}

Title: Application of article 68 penal code to cases of incomplete exclusion of imputability and multiple recidivism

Sumario: 1. Cuestiones preliminares. 2. Justificación parcial y semiimputabilidad. 3. Referencia al error en los presupuestos de hecho de una causa de justificación. 4. Justificación parcial y concurrencia de más de dos circunstancias agravantes. 5. Semiimputabilidad y multirreincidencia. Conclusiones. Referencias bibliografícas.

Resumen: Se aborda en este trabajo el análisis de las relaciones entre la determinación de la pena prevista por el artículo 68 del Código Penal y el límite máximo de internamiento de acuerdo con las prescripciones del artículo 104.1 del mismo texto legal. Se estudian asimismo las prioridades de subsunción entre los arts. 68 y 66.1.7. a del Código Penal y se hace una referencia al error en los presupuestos de hecho de una causa de justificación en caso de exceso intensivo por error en la legítima defensa.

Palabras clave: Justificación parcial, imputabilidad disminuida, marco penal, medida de internamiento, exceso intensivo por error, reincidencia, agravación.

Abstract: This paper addresses the analysis of the relationships between the determination of the criminal penalty provided by article 68 of the Penal Code and the maximum limit of internment in accordance with the prescriptions of article 104.1 of the same legal text. Subsumption priorities are also studied between arts. 68 and 66.1.7th of the Penal Code and a brief reference is made to the error in the factual 
assumptions of a justification cause in case of intensive excess due to error in legitimate defense.

Keywords: Partial justification, diminished responsibility, criminal framework, internment measure, intensive excess due to error, recidivism, aggravating circumstance.

\section{Cuestiones preliminares}

El artículo 68 del Código Penal plantea problemas muy diversos y complejos.

Entre otros, pueden ser destacados los siguientes:

a) El carácter facultativo u obligatorio de la rebaja del marco penal en un grado.

b) El régimen de prioridad entre los artículos 68 y 66.1.7. ${ }^{\mathrm{a}} \mathrm{CP}$.

c) La compatibilidad, total o parcial, o la incompatibilidad total entre el art. 68 y las reglas de determinación de la pena del art. 66.1 CP.

d) La exigencia de determinación de un nuevo marco penal tras la aplicación del art. $68 \mathrm{CP}$.

e) La exigencia de determinación de un nuevo marco penal por aplicación del art. 66.1 tras la previa rebaja en dos grados del marco penal en virtud del art. $68 \mathrm{CP}$, en especial, en caso de multirreincidencia.

f) El sometimiento a las reglas de extensión tras una subida del marco penal posterior a una rebaja en más de un grado.

g) La referencia a las circunstancias personales en el art. $68 \mathrm{CP}$.

h) Las relaciones del art. 68 con el art. $104 \mathrm{CP}$.

i) En particular, la reducción, o no, del límite máximo de la medida de internamiento en caso de justificación parcial o de semiimputabilidad.

j) La aplicación automática de agravantes genéricas para el semiimputable por el incremento de la culpabilidad pese a su imputabilidad disminuida.

En el presente trabajo se hará referencia a todos ellos salvo al primero y al último. Al primero, porque parece un caso cerrado en favor de la rebaja obligatoria del marco penal en un grado y facultativa en dos. Y, al último, porque excede las pretensiones de esta investigación; aunque sí será objeto de mención en las reflexiones finales. 


\section{Justificación parcial y semiimputabilidad}

Con la referencia a una determinación judicial de la pena en sentido estricto se alude al arbitrio de que dispone el Juez para moverse en el intervalo fijado por las reglas de determinación del marco penal y las reglas de extensión ${ }^{1}$. Esta determinación judicial de la pena se concibe como una fase de la determinación de la pena, posterior a la fase de la determinación legal, y se considera guiada por los criterios mencionados

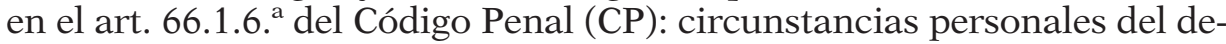
lincuente y mayor o menor gravedad del hecho; criterios que son tomados como específicos para la determinación judicial de la pena cuando no concurren circunstancias agravantes o atenuantes, y como criterios generales cuando ya han quedado atrás las reglas de extensión en caso de concurrencia de circunstancias agravantes, atenuantes, o de ambas ${ }^{2}$.

En tanto no es objeto de este trabajo el estudio de la determinación judicial de la pena, han de quedar a un lado, tanto el análisis de los criterios fijados por el art. 66.1.6. ${ }^{\mathrm{a}} \mathrm{CP}$, como el estudio de las relaciones entre los apartados 6. ${ }^{\circ}$ y $7 .^{\circ}$ del art. $66.1 \mathrm{CP}$. Como breve referencia al art. 66.1.6. ${ }^{\mathrm{a}} \mathrm{CP}$, se puede advertir que con la mayor o menor gravedad del hecho «se alude a la magnitud graduable de lo injusto, al desvalor de la acción y al desvalor del resultado, de forma que al mayor o menor desvalor le ha de corresponder mayor o menor pena dentro del marco penal $»^{3}$. «Pero por lo que se refiere a las circunstancias personales del

1 Una vez asignado el marco penal concreto que corresponde al delito -o delitos, en caso de concurso--, el Juez dispone de arbitrio para moverse dentro de dicho marco. Es la fase de la determinación judicial de la pena en sentido estricto, MiR Puig, S., Derecho Penal. Parte General, $10^{\mathrm{a}}$ edición, $2^{\mathrm{a}}$ reimpresión, en colaboración con GómEz MARTín, V., VALIENTE IváŃEZ, V., Reppertor, Barcelona, 2016, 31/53, p. 768.

2 «Esta precisión, que de manera técnicamente incorrecta circunscribe el Código Penal a los casos de ausencia de circunstancias, es generalizable a otras situaciones, ya que enuncia un principio general de determinación de la pena concreta», Molina FernándEZ, F., Memento Penal 2021, Molina Fernández, F., (Coord.), Lefebvre, Madrid, 2020, marginal 5527. De acuerdo con los criterios del art. 66.1.6. ${ }^{\mathrm{a}} \mathrm{CP}$, se procede a la individualización judicial de la pena y se obtiene la pena concreta, DíEz RipolLés, J.L., Derecho penal español. Parte General, $5^{\text {a }}$ edición, Tirant Lo Blanch, Valencia, 2020, p. 797. De otra opinión, negando el carácter de regla general a este precepto, Mapelli CafFarena, B., Las Consecuencias Jurídicas del Delito, $5^{\text {a }}$ edición, Thomson Reuters-Civitas, Cizur Menor (Navarra), 2011, p. 290. También, El alcance de esta regla «no puede ser más residual en el sistema español de determinación de la pena, puesto que este criterio [las circunstancias personales del delincuente] es destinado al último estadio del proceso de medición, después de haber realizado las demás operaciones sobre el marco penal que el resto de normas penológicas establecen», OBREGón GARCíA, A. «La exclusión social en la determinación de la pena: aplicabilidad de la eximente de alteraciones en la percepción (art. 20.3 CP) y de otras alternativas», Sistema penal y exclusión social, Benito SÁnchez, D., Gómez Lanz, J. (Dirs.), Thomson Reuters-Aranzadi, Cizur Menor (Navarra), 2020, p. 104.

3 Boldova Pasamar, M.A., "Aplicación y determinación de la pena», Lecciones de Consecuencias Jurídicas del Delito, $5^{\text {a }}$ edición, Gracia Martín, L., Boldova Pasamar, M.A., AlastUey Dobón, C., Tirant Lo Blanch, Valencia, 2016, p. 125; vid. CASTElló Nicás, N., Arbitrio 
delincuente, que no se limitan únicamente a las que tienen que ver con la culpabilidad, sino que pueden estar relacionadas también con necesidades preventivas, no es fácil establecer de antemano cuáles hay que tomar en consideración y en qué sentido hacerlo (para atenuar o para agravar), siendo preciso atender en cada supuesto concreto al razonamiento ofrecido por el juez en la sentencia (art. 72)» ${ }^{4}$. «Si estos criterios previstos en la Ley se interpretan a su vez de acuerdo con el vigente marco constitucional, se puede concluir afirmando que la pena impuesta debe ser proporcional a la gravedad del injusto culpable y, al mismo tiempo, consecuente con su finalidad preventiva, particularmente con la preventivo especial positiva o resocializadora si se trata de una pena privativa de libertad $»^{5}$. Además de esta finalidad eminentemente preventivo-especial, advierte CÁMARA ARROYO que es posible moderar la imposición de una pena que resultaría excesiva atendiendo a las circunstancias socioeconómicas del autor del delito, y que ello sea percibido como justo por la sociedad. En este sentido, la expresión introducida en el artículo 66.1.6. ${ }^{\mathrm{a}} \mathrm{CP}$ abre las puertas aunque de forma bastante limitada - a una mayor justicia social en el ámbito del Derecho penal ${ }^{6}$.

En cualquier caso, la pena concreta impuesta por el juez en la sentencia se puede acercar más al límite mínimo o al límite máximo del marco penal concreto, pero nunca podrá rebasarlos por defecto o por

judicial y determinación de la pena en los delitos dolosos (art. 66.1 del Código Penal), Comares, Granada, 2007, pp. 174-178. La STS 1297/2003, de 9 de octubre, rechaza, no obstante, que la gravedad del hecho tenga vinculación con la gravedad del delito, en tanto tal gravedad ha sido ya contemplada por el legislador para fijar la banda cuantitativa penal que le atribuye, y recurre a una noción tan abierta como las circunstancias fácticas «concomitantes» del supuesto concreto que se está juzgando; elementos de «todo orden» que fijarán «el concreto reproche penal que se estima adecuado imponer».

4 Boldova Pasamar, 2016, p. 125.

5 Gil Gil, A., Lacruz López, J.M., Melendo Pardos, M., Núñez Fernández, J., Consecuencias Jurídicas del Delito. Regulación y datos de la respuesta a la infracción penal en España, UNED, Dykinson, Madrid, 2018, p. 264. Parece pacífica la afirmación de que la mención de la personalidad del delincuente incluye una referencia inequívoca a consideraciones preventivo-especiales; así: GARCíA ARÁN, M., Los criterios de determinación de la pena en el Derecho Español, Universitat de Barcelona, 1982, pp. 225-226; GonZÁLEz CusSAC, J.L., «Arbitrio judicial y artículo 61.4. a del Código Penal: comentario a la sentencia de 20 de marzo de 1986», Poder Judicial, n 4, 1986, pp. 141-154; SAlinero Alonso, C., Teoría general de las circunstancias modificativas de la responsabilidad criminal y artículo 66 del Código Penal, Comares, Granada, 2000, pp. 161-162; CASTElló NiCÁs, 2007, pp. 168-174; Demetrio Crespo, E., Prevención general e individualización judicial de la pena, Ediciones Universidad de Salamanca, 1999, pp. 305-307; no obstante, en debate con DEMETRIO CRESPo, vid. FEIJoo Sánchez, B., «Individualización de la pena y teoría de la pena p r o porcional al hecho. El debate europeo sobre los modelos de determinación de la pena», InDret Penal, Barcelona, 1/2007, pp. 10-13.

6 CÁmARA ARRoYo, S., "Justicia social y Derecho penal: individualización de la sanción penal por circunstancias socioeconómicas del penado (arts. 66.1.6, 20.7 CP y 7.3 LORRPM)", Anuario de Derecho Penal y Ciencias Penales, nº 68, 2015, p. 251. 
exceso $^{7}$. A su vez, la necesidad preventivo especial se valora en atención a las circunstancias personales del delincuente, expresión que no solo se vincula, por tanto, a su grado de culpabilidad, sino a todos los factores indicativos de su potencial resocializador y de su riesgo de reincidencia, tales como su situación personal, familiar o laboral ${ }^{8}$.

No obstante, sí conviene mencionar que la determinación judicial de la pena precede a la determinación legal en la selección de la pena cuando el CP ofrece para un tipo concreto penas alternativas, con las importantes consecuencias que de ello se pueden derivar para la aplicación de medidas de seguridad privativas de libertad. «[C]uando las penas principales se prevén como alternativas, el juez debe optar, ya en esta fase inicial [de determinación del marco penal abstracto] y según su prudente arbitrio, por aplicar una u otra clase de pena» ${ }^{9}$.

«Un ámbito especialmente problemático inserto dentro de la fase general de individualización penal está constituido por la decisión judicial de pena alternativa, esto es, por aquellos supuestos en que la clase de consecuencia jurídica atribuida por el legislador penal a la comisión de un delito se presenta como una opción disyuntiva al juez, quien debe, en consecuencia, optar por un tipo de sanción específica de entre aquellas (posibles) que se prevén al efecto. Este tipo de decisión se presenta normalmente en el CP entre las alternativas legales de una pena privativa de libertad y una pena pecuniaria, constituyendo la gran mayoría de los casos una elección exclusiva entre la prisión -la pena privativa de libertad por excelencia- y la multa» ${ }^{10}$. El principal problema asociado a la decisión de la clase de pena alternativa radica en la ausencia de criterios legales explícitos que orienten al juez en su elección. «Se trata, en consecuencia, de una decisión cuya adopción supone un alto grado de ejercicio de discrecionalidad judicial, discrecionalidad que no se encuentra sujeta formalmente a baremos normativos explícitos» ${ }^{11}$. Esta decisión ha de quedar sujeta a las exigencias y cometidos de los fines del Derecho penal que se estimen como de admisible incidencia en la fase de individualización judicial de la sanción: gravedad del hecho y circunstancias personales del delincuente ${ }^{12}$. La mayor o menor gravedad del hecho no alude a la comparación del delito que se juzga con otros delitos: a mayor gravedad del delito - mayor desvalor de injusto, siendo normal la culpabilidaddeberá por regla general optarse por la pena más aflictiva, la prisión; y,

7 Gil Gil, Lacruz López, Melendo Pardos, Núñez Fernández, 2018, p. 264.

Ibidem.

9 Ibidem, p. 240. Para la naturaleza del delito en caso de penas alternativas, véase STS 392/2017, de 31 de mayo.

10 Besio Hernández, M., Los criterios legales y judiciales de individualización de la pena, Tirant Lo Blanch, Valencia, 2011, p. 573.

11 Ibidem, p. 574.

12 Ibidem, p. 575. 
del mismo modo, a menor desvalor de injusto y normal o menor culpabilidad, deberá tenderse a la opción menos aflictiva, la pena de multa ${ }^{13}$.

Es importante atender al hecho, señalado con acierto por GARCía ALBERO, de que la medida de internamiento para el semiinimputable solo podrá ser aplicada cuando la pena impuesta sea privativa de libertad. "Requisito éste que hay que interpretar en sus estrictos términos: no basta para ello con que el delito estuviere conminado con pena privativa de libertad en abstracto si la pena concreta impuesta no es privativa de libertad $-v$. gr., por tratarse de un delito conminado con pena alternativa de prisión o multa-» ${ }^{14}$.

De acuerdo con las reglas de los arts. 101, 102 y 103 CP, para la fijación del límite máximo de la medida de internamiento en caso de inimputabilidad plena habrá que estar a la pena individualizada: el internamiento no podrá exceder del tiempo que habría durado la pena privativa de libertad si el sujeto hubiera sido declarado responsable.

La jurisprudencia de TS ha ido paulatinamente modificando una primera tendencia a considerar la pena abstracta como límite máximo de internamiento en dirección a una pena algo más concreta. El Acuerdo del Pleno no Jurisdiccional de la Sala Segunda del TS, de 31 de marzo de 2009, señaló que «la duración máxima de las medidas de internamiento se determinará en relación a la pena señalada en abstracto para el delito de que se trate». Esta referencia a la pena abstractamente aplicable al hecho cometido, «entendemos que ha de referirse a la prevista en el correspondiente artículo definidor del delito teniendo en cuenta lo dispuesto en los arts. 61 a 64 a propósito del grado de ejecución (consumación y tentativa) y de participación (autoría y complicidad) y sin consideración a las circunstancias agravantes o atenuantes de carácter genérico (arts. 21 , 22 y 23)», STS 216/2012, de 1 de febrero. «La cuantía concreta de ese límite máximo ha de determinarse prescindiendo de la culpabilidad, que es el fundamento de la pena, culpabilidad que no existió por la mencionada inimputabilidad», STS 705/2017, de 25 de octubre. "[L]a pena que figura como límite de la medida de seguridad que cabe imponer en caso de exención de responsabilidad criminal, conforme a lo dispuesto en el artículo 101.1 del Código Penal (...), es la que tenga la duración que correspondería de haber sido declarado responsable el autor (...). Pero tal fijación ha de hacerse en abstracto, es decir sin tomar en consideración las circunstancias modificativas. No obstante, cuando se trata de un tipo de ejecución imperfecta, la pena que corresponde es la que vendría

$13 \quad$ Ibidem, p. 577.

14 García Albero, R., «Artículo 104», Comentarios al Código Penal Español. Tomos I y II, Quintero Olivares, G. (Dir.), $7^{\mathrm{a}}$ edición, Thomson Reuters-Aranzadi, Cizur Menor, 2016, Presupuestos de aplicación de la medida de seguridad al semiinimputable (formato digital).

(C) UNED. Revista de Derecho Penal y Criminología, 3. ${ }^{a}$ Época, n. ${ }^{\circ} 24$ (2020) 
determinada por ese dato", STS 33/2018, de 23 de enero; también, STS 34/2020, de 6 de febrero ${ }^{15}$.

Con carácter general, GRACIA MARTín considera que la referencia del art. 6. ${ }^{\circ}$. $\mathrm{CP}$ a la pena abstracta respecto de las medidas de seguridad (las medidas de seguridad no pueden resultar de mayor duración que la pena abstractamente aplicable al hecho cometido), y en atención a los diferentes fundamentos de ambas consecuencias jurídicas, debe entenderse dirigida a la pena prescrita en el correspondiente precepto de la Parte Especial, sin consideración a los grados de participación y de ejecución del delito ${ }^{16}$.

Esta apreciación se corresponde con la crítica del autor al método de determinación del límite máximo de las medidas de seguridad ${ }^{17}$.

Por el contrario, en la teoría de la medición de la pena, aunque se suele considerar que la pena abstracta es la que establece el precepto de la Parte Especial correspondiente al delito de que se trate, lo correcto, sin embargo, es que «las reglas de determinación de la pena en función de los grados de participación y de ejecución del delito no pueden considerarse reglas de concreción de una pena abstracta, sino reglas de fijación de la pena abstracta misma. Puesto que, por ejemplo, el cómplice no realiza el tipo de la Parte Especial, la pena establecida en el precepto correspondiente no puede ser la pena abstracta que corresponde al hecho del cómplice. Esta solo puede serlo la pena que abstractamente establezca el Código para el hecho realizado por el cómplice, que será la fijada por la regla específica que establezca la pena para la complicidad (art. 63)» ${ }^{18}$.

Pese a lo muy acertado de esta última apreciación, la tesis de GRACIA MARTín es, a mi entender, muy sólida salvo quizás en una implícita referencia del art. $6 .{ }^{\circ} 2 . \mathrm{CP}$ al hecho cometido por quien va a sufrir la medida; persona que, en caso de tentativa, no ha cometido un delito consumado $\mathrm{y}$, en caso de complicidad, no ha cometido el hecho del autor. El art. 6. ${ }^{\circ} 2$. CP apunta al desvalor objetivo del hecho del inimputable o del semiimputable para la determinación de ese límite máximo, y no al desvalor del hecho de otro o al desvalor de otro hecho no realizado ${ }^{19}$.

15 Para las diferentes soluciones doctrinales y jurisprudenciales, vid. GIL GIL, LACRUZ López, Melendo Pardos, NúÑEz Fernández, 2018, pp. 365-367.

16 Gracia Martín, L., "Las medidas de seguridad y reinserción social», Lecciones de Consecuencias Jurídicas del Delito, $5^{\text {a }}$ edición, Gracia Martín, L., Boldova Pasamar, M.A., Alastuey Dobón, C., Tirant Lo Blanch, Valencia, 2016, pp. 198-199.

17 Vid. Gracia Martín, 2016, p. 197.

18 Ibidem, p. 198.

19 Véase el acertado análisis que de los límites del art. 6.2 CP hace ALONSO RIMO, A., «Medidas de seguridad y proporcionalidad con el hecho cometido (a propósito de la peligrosa expansión del Derecho penal de la peligrosidad)», Estudios Penales y Criminológicos, $\mathrm{n}^{\circ} 29,2009$, pp. 115-120. 
A diferencia de lo prescrito para la inimputabilidad plena, el artículo $104 \mathrm{CP}$ remite para la semiimputabilidad a la pena prevista por el Código para el delito «El artículo 104 establece, textualmente, una fórmula diversa a la manejada por los artículos 101 a 103 en punto al establecimiento del límite máximo de cumplimiento de la medida de seguridad privativa de libertad. En efecto, mientras que tratándose de inimputables, el límite se cifra en el 'tiempo que habría durado la pena privativa de libertad', dispone el artículo 104 que el eventual internamiento del semiinimputable no exceda 'de la pena prevista por el Código para el delito'» ${ }^{20}$.

Un importante factor de incertidumbre viene provocado por el hecho de que la pena de la Parte Especial señala un marco penal, sin que quede claro si el límite máximo de la medida lo da el límite mínimo o el máximo de ese marco penal. En los supuestos de semiimputabilidad hay que determinar la pena con unos límites mínimo y máximo, a diferencia de la medida de seguridad, que únicamente pide un límite superior, pues su fundamento es la peligrosidad del sujeto (de modo que la medida decae cuando decae la peligrosidad, y ello con independencia de las exigencias del sistema vicarial fijado por el art. 99 del CP).

Parece que la referencia implícita siempre lo es al límite máximo, pero no hay que desatender que, sin concurrencia de circunstancias agravantes ni atenuantes, las circunstancias personales del delincuente pueden ser el factor decisivo que conduzca a la aplicación del límite mínimo del marco penal en la determinación judicial de la pena. Por ello, resulta de interés la distinción que ofrece DÍEZ RIPOLLÉS entre pena concreta para la determinación del límite máximo de internamiento del inimputable y pena abstracta para la semiimputabilidad, que se corresponderá «con la duración del límite mínimo del marco abstracto de la pena privativa de libertad aplicable al semiimputable» ${ }^{21}$.

Los semiimputables pueden verse sometidos, además de a una pena atenuada, a una medida de seguridad de duración no superior a la pena prevista legalmente para el delito, "pero seguramente superior a la que correspondería al imputable que hubiera realizado los mismo hechos», con lo que «se crea aquí una situación de desigualdad que ha de corregir el aplicador del Derecho, por más que en este caso el legislador no haya facilitado su trabajo» ${ }^{22}$.

Como se vio más arriba, la jurisprudencia del Tribunal Supremo más reciente comienza a orientarse, para la inimputabilidad plena, hacia la

20 García Albero, 2016, Artículo 104: La duración de la medida de internamiento impuesta al semiinimputable (formato digital).

21 Díez Ripollés, 2020, p. 817.

22 Mapelli Caffarena, B., Terradillos Basoco, J., Las Consecuencias Jurídicas del Delito, 3ª edición, Civitas, Madrid, 1996, p. 210. 
pena prevista en el específico artículo que castiga el delito, pero teniendo en cuenta la individualización que proceda en cuanto al grado de ejecución del mismo y el grado de participación del sujeto, y dejando de lado las circunstancias atenuantes y agravantes de carácter genérico ${ }^{23}$. La orientación hacia la pena abstracta en caso de semiimputabilidad es, sin embargo, quizás la opinión más extendida en la doctrina para la fijación del límite de la medida de seguridad de internamiento. Así, en los supuestos de eximente incompleta la pena-presupuesto será la pena privativa de libertad concretamente impuesta al sujeto semiimputable; y el límite será el de la pena abstracta señalada en el tipo penal correspondiente $^{24}$. "La extensión temporal de la medida de seguridad puede superar (...) a la de la pena impuesta, dado que aquella se establece sobre la base de la peligrosidad del sujeto y esta sobre su grado de culpabilidad» ${ }^{25}$. Para determinar la expresión del art. 104.1 («pena prevista por el Código para el delito»), diferente de las empleadas en los arts. 6. ${ }^{\circ}$ 2. y 101.1, 102.1 y 103.1, parece haber un cierto consenso doctrinal en tanto la opinión mayoritaria concibe que la misma se corresponde con «el límite máximo del marco penal de la figura delictiva cometida por el sujeto en atención al grado de ejecución alcanzado y al grado de participación, sin considerar las circunstancias atenuantes y agravantes que pudieran concurrir» ${ }^{26}$.

Se separa de esta línea general GARCía ALBERo, quien advierte que no exceder de la pena prevista por el Código para el delito supone cabalmente tomar el límite superior del marco genérico del correspondiente delito como frontera máxima de cumplimiento: circunstancia que presupone, en los términos del artículo 66, partir hipotéticamente de la mayor gra-

23 Vid. Jorge Barreiro, A., Rodríguez Horcajo, D., Memento Penal 2021, Molina FERnÁndez, F., (Coord.), Lefebvre, Madrid, 2020, Marginal 5939, con diversas referencias jurisprudenciales.

24 Jorge Barreiro, Rodríguez Horcajo, 2020, Marginal 5938. Como advierte García AlBERo respecto de las penas de prisión inferiores a tres meses, su preceptiva sustitución, por imperativo legal, no perjudica el que se haya impuesto una pena privativa de libertad. El tenor literal del artículo 104 no impide por ello imponer, además de la pena sustitutiva, una medida de internamiento que habrá de ejecutarse conforme al sistema establecido en el artículo 99. Sin embargo, la posibilidad que ofrece la interpretación textual del precepto ha de ceder frente a consideraciones teleológicas, vinculadas al principio de proporcionalidad que rige en la imposición de las medidas de seguridad: si la ley ha querido evitar la privación de libertad cuando al plenamente imputable no le hubiese sido impuesta, tal idea rectora subsiste cuando la situación es solo parcialmente diversa, a saber, cuando pese a su imposición en el fallo, dicha privación tampoco se hubiera llevado a cabo: ello afecta, por tanto, a las penas de prisión sustituidas ex artículo 71.2. La anterior reflexión no tiene sentido referida a las penas privativas de libertad impuestas pero suspendidas en su ejecución, pues lo lógico sería no suspender ab initio la pena, sino sólo posteriormente a la vista de los resultados conseguidos una vez alzado el internamiento, García Albero, 2016, Artículo 104: Presupuestos de aplicación de la medida de seguridad al semiinimputable (formato digital).

25 Gil Gil, Lacruz López, Melendo Pardos, Núñez Fernández, 2018, p. 375.

26 Ibidem, pp. 375-376. 
vedad posible del hecho, así como de la mayor culpabilidad del autor circunstancias personales del delincuente- ${ }^{27}$. No obstante, en opinión de este autor, tomar como referencia un tal juicio hipotético, cuando lo que realmente se ha afirmado en sentencia es una culpabilidad disminuida, parece un despropósito ${ }^{28}$. En consecuencia, debería, por exigencias del principio de proporcionalidad, interpretarse al menos la previsión del artículo 104 en los mismos términos a como se ha efectuado con relación a los artículos 101, 102 y 103: en definitiva, la duración de la medida de internamiento acordada no podrá ser superior a la de la pena de prisión que se hubiera impuesto caso de no concurrir la eximente incompleta ${ }^{29}$. Se trata en definitiva de entender que la pena prevista en el Código para el delito lo es para el delito concreta e históricamente realizado, esto es, teniendo en cuenta no sólo aspectos relativos a iter criminis y participación - lo que resultaría obligado incluso desde el entendimiento de la fórmula como pena abstracta prevista para el delito-, sino a la eventual concurrencia de circunstancias modificativas de la responsabilidad criminal (excepción hecha, obviamente, de las que han sido valoradas vía exención incompleta) ${ }^{30}$. En todo caso, y si se estimara que la diversa dicción legal del artículo 104 respecto del 101 ha de tener algún sentido, no sería lógico prescindir, al menos, de la pena resultante de aplicar las reglas de autoría y participación ${ }^{31}$.

En los supuestos de concurso real de delitos, si el sujeto en cuestión es condenado por la comisión de varios delitos a los que pueda corresponder individualmente una medida de seguridad privativa de libertad, y sus circunstancias personales hacen que proceda la imposición de una de idéntica naturaleza por todos ellos, la medida de seguridad impuesta debe ser única, pero su límite máximo ha de calcularse sumando la duración de las distintas penas de prisión que hubieran correspondido por la pluralidad de delitos ${ }^{32}$. En el concurso real, el triple del tiempo por el que se imponga la pena más grave atiende a las penas concretas ${ }^{33}$.

En el concurso medial, el límite mínimo de la pena «superior» (art. $77.3 \mathrm{CP}$ ) es un día más de la pena concreta por la infracción más grave, y el límite máximo la suma de las penas concretas. Se trata de una pena ex novo que toma como base todas las penas concretas totalmente individualizadas. La referencia posterior al art. 66 ha de entenderse dirigida a

27 García Albero, 2016, Artículo 104: La duración de la medida de internamiento impuesta al semiinimputable.

28 Ibidem.

29 Ibidem.

30 Ibidem.

31 Ibidem.

32 Jorge Barreiro, Rodríguez Horcajo, 2020, marginal 5940. Vid. SSTS 890/2010, de 8 de octubre, y 34/2020, de 6 de febrero.

33 Boldova Pasamar, 2016, p. 133. 
los factores de determinación judicial de la pena (mayor o menor gravedad del hecho y circunstancias personales del delincuente) ${ }^{34}$.

En el concurso ideal cabe atender a la pena condicionalmente definitiva, para la que se tienen en cuenta las circunstancias modificativas de la responsabilidad, ordinarias y extraordinarias, así como los factores de individualización de la pena; o, en su defecto, a la penalidad concreta acumulada (la suma de las penas individuales determinadas totalmente) ${ }^{35}$.

Llegados aquí, conviene detenerse en una enumeración de todas las alternativas abiertas para la determinación del límite máximo de internamiento en caso de semiimputabilidad:

1. Pena de la Parte Especial (o pena del tipo).

2. Pena del hecho (con grado de ejecución y participación).

3. En su caso, pena del hecho con rebaja en uno o dos grados por justificación incompleta (art. 68) ${ }^{36}$.

4. Pena con circunstancias agravantes y atenuantes que no afectan a la culpabilidad. Hay que advertir a este respecto que, en tanto hay eximentes que excluyen o disminuyen la culpabilidad sin previsión de medida de seguridad, no hay razón para que tales circunstancias no se contemplen en la determinación del límite máximo de la medida para el semiimputable. Así, por ejemplo, una semiimputabilidad sumada a una eximente incompleta de miedo insuperable.

No hay que olvidar que para que sea posible admitir la concurrencia del requisito de la comisión de un delito, junto al carácter típico y antijurídico de la conducta «será preciso constatar que no concurre ninguna otra eximente que afecte a ulteriores

34 Boldova Pasamar, 2016, p. 139 (cursivas añadidas). Vid. Circular FGE 4/2015, de 13 de julio.

35 Vid. Boldova Pasamar, 2016, pp. 138-139. Sobre el orden de aplicación de las reglas de determinación de la pena en caso de concurso real, ideal o medial, vid., por todos, GIL Gil, Lacruz LóPez, Melendo Pardos, NúÑez Fernández, 2018, p. 262-264.

36 El efecto atenuante de la eximente incompleta se puede acumular al anudado a la concurrencia de otras circunstancias atenuantes teniendo en cuenta las reglas $1 .{ }^{\mathrm{a}}$ y $2 .^{\mathrm{a}}$ del art. 66.1. Algunos autores entienden que la concurrencia de dos eximentes incompletas permitiría una rebaja máxima de hasta cuatro grados por la suma de los efectos atenuantes de cada eximente incompleta, Gil Gil, Lacruz LóPeZ, MElendo Pardos, NúÑEZ FERNÁNDEZ, 2018, p. 250. A favor de la acumulación de efectos en caso de concurrencia de mas de una eximente incompleta, Mir PUig, $P G$, 2016, 31/51, p. 767; Molina Fernández, 2020, marginal 5532. "Si concurren varias eximentes incompletas, sus efectos se suman», Molina Fernández, F., Mendoza Buergo, B., «La determinación de la pena. Las instituciones individualizadoras y los sustitutivos de las penas privativas de libertad», Manual de Introducción al Derecho Penal, Lascuraín SÁnchez, J.A. (Coord.), Boletín Oficial del Estado, Madrid, 2019, p. 222. 
elementos de la culpabilidad o a la punibilidad ${ }^{37}$. La mención legal al tiempo que habría durado la pena privativa de libertad si el sujeto hubiese sido declarado responsable (arts. 101, 102 y 103 CP para la inimputabilidad plena), "excluye como presupuesto fáctico legitimador de la aplicación de la medida de seguridad al hecho típico y antijurídico pero no culpable (por la concurrencia de un error de prohibición invencible o de una causa de exculpación basada en la inexigibilidad) o no punible (por la concurrencia de una eximente situada en esa sede). Ello porque en tales casos el sujeto no habría sido declarado penalmente responsable de haber sido imputable. Esta interpretación evita además que se coloque al inimputable o al semiimputable en una situación más gravosa que en el caso de haber sido considerado plenamente imputable» ${ }^{38}$.

5. Pena concreta sin atención a la circunstancia que condiciona la semiimputabilidad.

Dada la redacción del art $104 \mathrm{CP}$, parece difícil recurrir a la alternativa $5^{\mathrm{a}}$ de la enumeración anterior, resultando dudoso -aunque recomendable- el nivel número 4. Como veíamos más arriba, GARCÍA ALBERO, en atención a la dicción literal de este precepto, exigía, al menos, no prescindir de la pena resultante de aplicar las reglas de autoría y participación ${ }^{39}$.

En cualquier caso, a la exigencia expuesta por GARCÍA AlBERo hay que añadirle, también como mínimo, y en caso de concurrencia de una eximente incompleta que disminuya el injusto - por ejemplo, la legítima defensa incompleta de un semiimputable-, una disminución del límite máximo de internamiento para el semiimputable acorde con la correspondiente disminución del injusto y en atención a las exigencias de los arts. 21.1. ${ }^{\mathrm{a}}$ y $68 \mathrm{CP}$.

No hay que olvidar que el injusto es una magnitud graduable. Como señala Roxin, la antijuridicidad formal no permite aumentos ni distinciones cualitativas, pero la antijuridicidad material permite graduar el injusto según su gravedad, con importantes consecuencias para el grado de culpabilidad - determinado también por el injusto material del he-

37 Gil Gil, Lacruz López, Melendo Pardos, Núñez Fernández, 2018, p. 341.

38 Ibidem, p. 366 (cursivas añadidas).

39 García Albero, 2016, Artículo 104: La duración de la medida de internamiento impuesta al semiinimputable (formato digital). Resulta de interés en este punto la apreciación de Rodríguez Horcajo, para quien «la dicción del artículo 104 CP debe entenderse como una remisión a la pena que el Código Penal, en su plena aplicación (y, por tanto, aplicando las reglas previstas en la parte general - a excepción del art. 21.1. ${ }^{\mathrm{a}}$ CP-) asocia al delito», vid. Rodríguez Horcajo, D., "Las medidas de seguridad», Manual de Introducción al Derecho Penal, Lascuraín SÁNCHEZ, J.A. (Coord.), Boletín Oficial del Estado, Madrid, 2019, p. 277. 
cho-, para las ponderaciones de intereses propias de la comprobación de la antijuridicidad, e incluso para la exclusión de la responsabilidad o la definición de los contornos de la autoría mediata ${ }^{40}$. En el ámbito de la exculpación, es muy significativo el giro dado por Roxin en la solución a los problemas de concurrencia de inimputabilidad y estado de necesidad exculpante. En la segunda edición de su Parte General considera que "cuando las circunstancias concomitantes de un homicidio en sí amparado por el $\S 35$ [§ 35 del $S t G B$, donde se regula el estado de necesidad exculpante] demuestran que el enfermo mental -por ejemplo, porque entra entonces en un delirio homicida a la vista de la sangre- es peligroso para la colectividad, resulta totalmente adecuado imponer una medida de seguridad ${ }^{41}$. Por el contrario, en la tercera edición niega la aplicación al enfermo mental de una medida de seguridad si concurre una causa de exculpación, ya que «en tanto el enfermo mental no se comporta de manera distinta a un autor normal capaz de culpabilidad, no existe ningún motivo para imponerle sanciones penales. La sola peligrosidad no es, como por lo demás en Derecho penal, suficiente para ello. De otro modo, el hecho realizado en legítima defensa por un enfermo mental debería por sí solo motivar una medida de seguridad, lo que naturalmente no puede entrar a debate» ${ }^{42}$.

\section{Referencia al error en los presupuestos de hecho de una causa de justificación}

Hay acuerdo doctrinal en que nada obsta a la aplicación conjunta de una eximente incompleta basada en la disminución del injusto y un error de prohibición vencible. «Las reglas de determinación de la pena en caso de error vencible sobre la antijuridicidad (art. 14.3 CP: habrá que rebajar la pena en uno o dos grados) también han de ser tenidas en cuenta para establecer el marco penal concreto y se aplican a todas las infracciones penales» ${ }^{43}$.

40 Roxin, C., Derecho Penal. Parte General. Tomo I. Fundamentos. La estructura de la teoría del delito, traducción de la $2^{a}$ edición alemana (1994) por LuZÓn PEÑA, DíAz y GARCía Conlledo, y De Vicente Remesal, Civitas, Madrid, 1997, 14/7, p. 559.

41 Roxin, $P G$, (tr. $2^{\mathrm{a}}$ ), 1997, 19/53, p. 817.

42 Roxin, C., Strafrecht. Allgemeiner Teil. Band I. Grundlagen. Der Aufbau der Verbrechenslehre, 3. Auflage, C.H. Beck, München, 1997, 19/57, p. 750; también, Strafrecht. Allgemeiner Teil. Band I. Grundlagen. Der Aufbau der Verbrechenslehre, 4. Auflage, C.H. Beck, München, 2006, 19/61, p. 879.

43 Gil Gil, Lacruz López, Melendo Pardos, Núñez Fernández, 2018, p. 241. Vid. Ruiz De Erenchun Arteche, E., Sistema de Penas, Reglas de Determinación de la Pena y Suspensión de la Ejecución de la Pena, Thomson Reuters-Aranzadi, Cizur Menor (Navarra), 2017, pp. 124-125. 
Pero, en tanto el error en los presupuestos de hecho de una causa de justificación es incardinado por parte de la doctrina en el art. 14.1 del CP, la solución precisa de supuestos como, por ejemplo, el error en cuanto al exceso intensivo en la legítima defensa puede llegar a ser muy intrincada. Y para aproximarse a ella resulta imprescindible una referencia a las relaciones entre los arts. 14.1 y $68 \mathrm{CP}$.

Las relaciones entre el exceso intensivo en la legítima defensa y el error en los presupuestos de hecho de una causa de justificación son múltiples y muy complejas ${ }^{44}$. Aquí me voy a referir solamente a un supuesto: aquel en el que el exceso intensivo se produce por un error en los presupuestos de hecho circunscrito a la necesidad racional del medio empleado.

Si solamente tenemos un exceso intensivo en la legítima defensa de un tipo, por ejemplo, de homicidio, obtenemos una rebaja de la pena en uno o dos grados; eximente incompleta de legítima defensa (concurre una agresión ilegítima pero falta la necesidad racional del medio empleado): 5-10 años menos un día de prisión, o 2 años y 6 meses-5 años menos un día de prisión.

Si solamente tenemos un error de presupuestos que afecta a la propia agresión ilegítima, la pena anterior no será la correcta para la doctrina que orienta el error de presupuestos al art. $14.1 \mathrm{CP}$. La pena del párrafo precedente irá dirigida a quien, por ejemplo, sabe que puede reducir al agresor por la fuerza y aun así prefiere matarlo. Pero para quien imagina una agresión ilegítima que no existe, la pena en caso de error vencible (de tipo) será la propia del delito imprudente; en nuestro ejemplo, de 1 a 4 años de prisión (art. 142.1 CP).

De estos dos casos precedentes hay que distinguir el denominado exceso intensivo por error.

La diferencia entre el exceso por error y el error respecto de la agresión ilegítima es muy importante, pues en el error respecto de la agresión ilegítima no hay una agresión ilegítima y en el exceso intensivo por error sí la hay.

En el error respecto de la agresión ilegítima no concurre ningún presupuesto material esencial de la legítima defensa ${ }^{45}$. Si partimos de

44 Véase Mir Puig, $P G, 10^{\mathrm{a}}, 2016,16 / 85$ pp. 457-458; Bolea Bardón, C., «El exceso intensivo en la legítima defensa putativa», Anuario de Derecho Penal y Ciencias Penales, tomo 51, 1998, pp. 613-641. «Con la expresión exceso intensivo en la defensa putativa se alude a aquellos supuestos en que el sujeto cree erróneamente que es victima de una agresión que en realidad no existe; y, en su supuesta defensa, traspasa los limites que hubieran existido en caso de que la necesidad de defensa fuera real», BOLEA BARDón, 1998, p. 633.

45 Aquí no cabe hablar de una eximente incompleta, "pues la aplicación de la eximente incompleta en caso de que falte algún elemento no esencial queda condicionada a la concurrencia de los elementos esenciales de la eximente», BOLEA BARDón, 1998, p. 635. 
la base de que el error es vencible, habrá, muy resumidamente, dos soluciones diferentes según sigamos la teoría del dolo o la teoría de la culpabilidad. Para esta última, una rebaja de la pena en uno o dos grados (14.3. CP). Para la teoría del dolo, un homicidio imprudente (1-4 años de prisión: art 142.1. CP) ${ }^{46}$.

Esta solución, no obstante, no sirve para el exceso intensivo por error, pues en él, como acabamos de ver, sí hay una agresión ilegítima. Si seguimos la teoría estricta de la culpabilidad, la determinación de la pena es muy sencilla: una primera rebaja de la pena en uno o dos grados por el exceso intensivo (arts. 20.4. ${ }^{\circ}, 21.1 .^{\mathrm{a}}$ y $68 \mathrm{CP}$ ) y otra rebaja de la pena en uno o dos grados, acumulada a la anterior, en virtud del error vencible de prohibición (art. 14.3. CP) ${ }^{47}$.

Pero si entendemos que el error en los presupuestos de una causa de justificación ha de excluir el dolo, la obtención de una solución exacta se complica severamente.

No se puede, como a veces se hace, acudir sin más al tipo imprudente, pues en tal caso estamos dejando sin respuesta la presencia efectiva de una agresión ilegítima, es decir, estamos tratando igual un caso en el que, por ejemplo, hay un acometimiento ilegítimo con intención homicida y otro en el que tal agresión solamente es imaginada en error vencible de presupuestos por el, por ejemplo, autor de un homicidio.

Expongo aquí una propuesta personal para la solución de estos complejos casos de exceso intensivo por error si se conciben como subsumibles en el art. 14.1 $\mathrm{CP}^{48}$ :

En el exceso por error puede hablarse de una justificación parcial hasta el límite de la conducta correcta y de un tipo imprudente cuya base de medición habrá de ser la correspondencia numérica entre los marcos penales conocidos. Así, si el defensor cree que la muerte del agresor es

46 Hay que advertir que «salvo en los casos en que la invencibilidad del error se extienda tanto a elementos esenciales como inesenciales (...), en las demás variantes de doble error sobre elementos esenciales e inesenciales (...), conforme al tratamiento que aquí se otorga a esta clase de error [error de tipo], habrá que mantener el castigo por injusto imprudente, siempre que el hecho dé lugar a un tipo de injusto imprudente expresamente previsto en la Ley», Bolea BARdón, 1998, p. 638. Véase, también, Baldó LaVILla, F., Estado de necesidad y legitima defensa, Bosch, Barcelona, 1994, pp. 317-320.

47 Desde la perspectiva del error de prohibición vencible, JiménEz Díaz resuelve acertadamente este problema. Así, dada una agresión ilegítima, «en el supuesto de que el error afecte a la racionalidad del medio, existe una situación real que hace necesaria la defensa, que tan sólo se ve excedida en su medida. Lo cual determina que parte del acto sea legítimo y sólo la otra parte (el exceso intensivo) no lo sea». Por tal razón, es necesaria una doble rebaja de la pena, «una por la legítima defensa incompleta y otra por el error vencible», Jiménez Díaz, M.J., El exceso intensivo en la legítima defensa, Comares, Granada, 2007, p. 135.

48 Vid. SÁnchez Dafauce, M., "Algunos problemas singulares de la antijuridicidad penal», Nuevo Foro Penal, nº 93, 2019, p. 107. 
el medio eficaz menos lesivo para salvar su vida pero ello no es cierto porque tenía a su alcance otro medio eficaz menos lesivo, y si su error es evitable, la mejor forma de determinar la pena es la siguiente: en primer lugar, se reduce la pena por el homicidio en uno o dos grados, p.ej. en un grado, 5-10 años -la pena que le hubiese correspondido al defensor si se hubiese excedido dolosamente-, y, después, se hace la correspondencia entre marcos penales. Si 10-15 años -homicidio doloso consumado-se corresponden con 1-4 años -homicidio imprudente grave: la pena que p.ej. le hubiera correspondido al hipotético defensor si de modo vencible hubiese creído que concurría una agresión ilegítima en realidad inexistente-, 5-10 años se corresponderán con 0,5-2,6 años. Este será el marco penal (si se rebaja la pena en un grado por la exención incompleta; para la rebaja en dos grados basta con repetir la operación con las nuevas cifras) dentro del que habrá que decidir la pena para el autor: de 6 meses a 2 años, 7 meses y 6 días de prisión.

\section{Justificación parcial y concurrencia de más de dos circunstancias agravantes}

Aunque será infrecuente un caso real que reúna estas condiciones, conviene abordar el estudio de estos supuestos antes de pasar a la evaluación conjunta de semiimputabilidad y multirreicidencia, pues "[1]a relación entre las reglas $4^{\mathrm{a}}$ y $5^{\mathrm{a}}$ [del art. $\left.66.1 \mathrm{CP}\right]$ debe entenderse como de alternatividad, resuelta a favor de la que impone una pena más severa (CP art. 8.4), que es la reincidencia cualificada ${ }^{49}$. Las subidas de marco penal recogidas en los apartados $4 .^{\circ}$ y $5 .^{\circ}$ del art. $66.1 \mathrm{CP}$ son ambas potestativas. Si el Tribunal no hace uso de la facultad que le otorga la regla 4. ${ }^{\mathrm{a}}$, entra subsidiariamente en aplicación la regla $3 .^{\mathrm{a} 50}$.

Las relaciones entre las reglas $4 .^{\mathrm{a}}$ y $5 .^{\mathrm{a}}$ del art. 66.1 , no obstante, no se agotan con el recurso al art. 8.4 CP. «Nada impide que en un caso concreto haya, a juicio del tribunal, razones materiales para aplicar la $4^{\mathrm{a}}$ y no la $5^{\mathrm{a}} \mathrm{o}$ al revés. En cualquiera de estos dos casos no habrá concurrencia de reglas, así que se aplicará sencillamente la que esté presente, teniendo en cuenta la agravante o agravantes restantes para determinar la pena exacta. Pero, si se dan los presupuestos para aplicar ambas, no se pueden acumular sus efectos, y el juez debe aplicar solo la regla $5^{\text {a }}$. Es discutible si, no dándose las circunstancias de ninguna de las dos reglas por separado, se podrían combinar de alguna manera para permitir la elevación en grado. En el caso de la regla $5^{\mathrm{a}}$ la respuesta es negativa: si la reincidencia por sí no tiene la suficiente entidad para aconsejar la elevación en grado, la respuesta no cambia porque haya otras agravan-

\footnotetext{
49 Molina Fernández, 2020, marginal 5541.

50 Ibidem, marginal 5537.
} 
tes. En el caso de la regla $4^{a}$, sin embargo, la respuesta debe ser otra. Al regularse aquí la concurrencia de agravantes, y serlo también la reincidencia, nada impide al juez tomar este dato adicional en cuenta para justificar la imposición de la pena superior en grado, pero siempre dentro de su mitad inferior ${ }^{51}$.

El prolongado y muy interesante debate que en este punto se plantea respecto de la concurrencia de una eximente incompleta y una o más agravantes, en términos muy generales, es el de la subsunción del supuesto, o bien en el art. 66.1.7. ${ }^{\mathrm{a}} \mathrm{CP}$, o bien, sucesivamente, en los arts. 68 y 66.1.3. ${ }^{\mathrm{a}}$ (o $\left.4 .^{\mathrm{a}}\right) \mathrm{CP}^{52}$.

La prioridad del actual art. 66.1.7. ${ }^{\mathrm{a}} \mathrm{CP}$ se pretende encontrar en la evitación de vacíos punitivos incomprensibles ${ }^{53}$. Como es sabido, el art. $68 \mathrm{CP}$ remite al art. 66 («sin perjuicio de la aplicación del artículo 66 del presente Código»). En el Pleno no Jurisdiccional celebrado el día 1 de marzo de 2005, la Sala Segunda del TS llegó al siguiente Acuerdo: «El art. $68 \mathrm{CP}$, cuando remite al art. $66 \mathrm{CP}$, no excluye ninguna de sus reglas, entre ellas la regla $8^{\mathrm{a}}$ ». De acuerdo con esta regla $8^{\mathrm{a}}$ : «Cuando los jueces o tribunales apliquen la pena inferior en más de un grado podrán hacerlo en toda su extensión».

En caso de concurrencia de una eximente incompleta con una circunstancia agravante, "si un Juez puede aplicar la mitad superior de la pena inferior en dos grados, resulta absurdo obligarle a aplicar la mitad superior para el caso de que opte por rebajar un grado, debiendo por tanto reconocérsele la posibilidad de aplicar el tramo intermedio, esto es, la mitad inferior de la pena inferior en un grado» ${ }^{54}$. Muy ilustrativa es al respecto la STS 17/1996, de 22 de enero, que considera "contrario a las más elementales reglas del sentido común» no reconocerle al Juez la facultad de castigar con alguna de las penas intermedias.

Para evitar esta distorsión, un importante sector doctrinal da prioridad, en la solución de nuestro caso, a la regla contenida en el art. 66.1.7. ${ }^{\mathrm{a}}$ $\mathrm{CP}$, es decir, a la regla prevista para la concurrencia de circunstancias agravantes y atenuantes. Así, en la compensación de las circunstancias atenuantes y agravantes del art. 66.1.7. ${ }^{\text {e }}$ "entran también las eximentes incompletas», habida cuenta de «la expresa referencia a la vigencia del art. 66 respecto a ellas» ${ }^{55}$. La eximente incompleta es una de las tres posibilidades abiertas en caso de concurrencia de atenuantes y ninguna

51 Ibidem, marginal 5541.

52 Vid. Mapelli CafFarena, 2011, pp. 287-304; BorJa JimÉnez, E., La aplicación de las circunstancias del delito, Tirant Lo Blanch, Valencia, 2015, pp. 110-117.

53 Vid. García ARán, M., Fundamentos y aplicación de penas y medidas de seguridad en el Código Penal de 1995, Aranzadi, Pamplona, 1997, p. 87.

54 Ruiz De Erenchun Arteche, p. 128, nota 33.

55 DíEZ RiPOLLÉs, 2020, p. 785. 
agravante (arts. 66.1.1. ${ }^{\mathrm{a}}, 66.1 . .^{\mathrm{a}} \mathrm{y}$ art. $68 \mathrm{CP}$ ); para la concurrencia de atenuantes y agravantes, resulta de aplicación el art. 66.1.7. ${ }^{\text {a56. }}$.

No obstante, parece que doctrina y jurisprudencia mayoritarias van paulatinamente orientándose en favor de la segunda solución, es decir, en favor de la aplicación sucesiva de los arts. 68 y $66.1 \mathrm{CP}^{57}$.

La STS 686/2015, de 28 de octubre, se aparta de la mencionada STS de 22 de enero de 1996 y concluye que el argumento tendente a impedir vacíos punitivos en los tramos intermedios tiene fuerza «pero carece de capacidad para quebrar la literalidad clara del texto legal. Es quizás algo sobre lo que el legislador podría reflexionar pero no permite soluciones por vía interpretativa». El interrogante que plantea la Sentencia se enuncia así: «concurriendo simultáneamente una eximente incompleta y una agravante, y una vez degradada la pena conforme a lo establecido en el art. 68, ¿hay que estar a lo establecido en el art. 66.1.7..$^{\text {a }}$ (discrecionalidad orientada por criterios pero no por reglas)?; o, por el contrario, ¿'sería de aplicación preferente la regla 3. ${ }^{a}$ del art. 66.1 CP (mitad superior de la pena degradada)?». Aunque la jurisprudencia no siempre ha sido unánime sobre este extremo, la aseveración del Pleno no jurisprudencial de 1 de marzo de 2005, referida al hecho de que la remisión del art. 68 al art. 66 no excluye ninguna de sus reglas, tampoco la incluida en el art. 66.1.8. ${ }^{\mathrm{a}}$, no tendría sentido si al juzgador le quedase abierta la discrecionalidad ofrecida por el art. 66.1.7. ; con tal interpretación «[n]o habría cuestión alguna en cuanto a la regla $8 .^{\mathrm{a}}$ y el debate del citado Pleno carecería de sentido». El Fiscal, por su parte, resalta cómo el inciso final del art. $68 \mathrm{CP}$ salva expresamente la aplicabilidad del art. 66, lo que no puede interpretarse más que en un sentido: «si se ha obtenido un nuevo marco penal derivado de la aplicación de la eximente bajando un único grado (si se hubiesen descendido dos se recuperaría la discrecionalidad total: art. 66.1.8. ${ }^{\mathrm{a}}$ ), dentro de la horquilla así fijada habrá que ajustarse a las reglas del art. 66: mitad inferior si hay una atenuante; mitad superior si concurre una agravante; compensación racional si concurren circunstancias de uno y otro signo». «Tiene razón el Fiscal. Eso es lo que se desprende de la literalidad del art. 68 CP. Si la Audiencia (...) optó por conferir a la exención incompleta una moderada eficacia concretada en una única degradación, dentro de la franja penal así obtenida deberá tomar en consideración el resto de circunstancias para concretar la penalidad». Además, «el art. 68 ha de considerarse regla especial frente al 66.1.7 ${ }^{\mathrm{a}}$, que solo contempla la concurrencia de circunstancias atenuan-

56 Gil Gil, Lacruz López, Melendo Pardos, Núñez Fernández, 2018, pp. 248-251.

57 Existe un cierto consenso en entender que las circunstancias de eficacia privilegiada quedarían al margen de la operación de compensación racional, BESIo HERNÁNDEZ, 2011, p. 535. La eximente incompleta permite siempre una reducción de la pena en uno o dos grados, incluso concurriendo una agravante, con la que no podrá compensarse, MAPelli CAFFarena, 2011, p. 297. 
tes y agravantes ordinarias y no las singulares del art. 21.1. CP» (STS $686 / 2015$, de 28 de octubre) ${ }^{58}$.

Aquí encontramos, en consecuencia, tres reglas importantes:

a) El art. 68 prima sobre el 66.1.7. ${ }^{\mathrm{a}} \mathrm{CP}$ en caso de concurrencia de circunstancias agravante y atenuantes.

b) Una vez aplicado el art. 68, la eximente incompleta deja de existir a los efectos de la aplicación posterior del art. 66.1 CP.

c) La liberación de la reglas de extensión recogida en el art. 66.1.8. ${ }^{\text {a }}$ $\mathrm{CP}$ solamente se produce cuando se aplica la pena inferior en más de un grado ${ }^{59}$.

En favor de la primera regla mencionada cabe añadir que, dado que la eximente incompleta actúa siempre como una atenuante muy cualificada, no queda claro, si se da preferencia al art. 66.1.7. ${ }^{\mathrm{a}}$, para qué ha redactado el legislador el art. 68, pues hubiera sido suficiente en tal caso una mención al carácter muy cualificado de las eximentes incompletas en el propio art. 66.1.2. ${ }^{\mathrm{a}} \mathrm{CP}$.

En la doctrina penal se pueden encontrar diversas referencias favorables a la prioridad del art. 68 sobre el $66.1 .7^{\mathrm{a}} \mathrm{CP}$.

Así, por ejemplo, Molina Fernández considera que la atenuación exigida por el art. 68 es obligatoria y «tiene lugar incluso aunque concurran circunstancias agravantes. El legislador ha querido privilegiar este caso respecto de otros, configurando no sólo un efecto atenuatorio muy cualificado, sino haciéndolo inmune al sistema restrictivo que se aplica en otras atenuantes cuando concurren agravantes» ${ }^{60}$. Se puede apreciar que «el art. 66 no contempla regla alguna para la concreción de la pena en caso de concurrir una eximente incompleta $\left(21.1^{\mathrm{a}}\right)$. En estos casos, según el art. 68, se impondrá la pena inferior en uno o dos grados atendiendo a los requisitos que falten o concurran y las circunstancias personales del autor. No hay ningún obstáculo para aplicar conjuntamente lo previsto en ambos artículos (Acuerdo del Pleno no Jurisdiccional de la Sala Segunda del TS de 1 de marzo de 2005). Únicamente habrá que tener presente que, en primer lugar, se procederá a la aplicación de la rebaja en uno o dos grados prevista en el art. 68, y posteriormente, lo

58 También, STS 725/2016, de 28 de septiembre.

59 Respecto de esta última conclusión, es de otra opinión MAPELLi CafFarena, quien reduce la eficacia del art. 66.1.8. ${ }^{\mathrm{a}}$ a las reglas contenidas en el mismo art. 66, pues, entre otras razones, el propio legislador muestra su voluntad de circunscribir sus efectos al ámbito del art. 66 CP, cuando en otras ocasiones decreta la incompatibilidad absoluta, 2011, pp. 290 y 298.

60 Molina FernándeZ, 2020, marginal 5529. 
que proceda en virtud del art. $66.1 »^{61}$. «Las eximentes incompletas, pese a estar previstas en el art. 21.1. ${ }^{\mathrm{a}} \mathrm{CP}$, tienen un estatus distinto al resto de las atenuantes. Esto lo demuestra el presente artículo [68 CP], el cual contiene una previsión expresa y taxativa sobre sus efectos, a diferencia de las atenuantes muy cualificadas o de las comunes, cuya incidencia en la pena viene recogida en el art. 66. En estos casos habrá que proceder a la degradación de la pena imperativamente en un grado y, facultativamente, en dos, y con independencia de que concurran circunstancias agravantes (STS 544/07, 21-6)» ${ }^{62}$. «Una vez degradada la pena en uno o dos grados, según falten más o menos requisitos, se procederá a aplicar las reglas del art. $66 \mathrm{CP}$ en sus propios términos a la pena resultante» ${ }^{63}$.

De la misma opinión es BESIO HERnÁNDEZ, para quien, al margen de la discusión relativa a si la eximente incompleta constituye o no una circunstancia atenuante propiamente dicha, «la especial operatividad normativa de la eximente incompleta impide su consideración al interior del ejercicio de compensación racional, toda vez que ésta produce sus efectos en un momento anterior a la funcionalidad del resto de circunstancias (y de la operación de compensación), determinando un marco penal intermedio entre el marco abstracto y el marco penal concreto a partir del cual inciden las demás circunstancias modificativas, sistemática que se encuentra reafirmada por el vigente art. $68 \mathrm{CP}^{64}$.

La concurrencia de una eximente incompleta produce una disminución en grado de la pena aunque concurra una agravante ${ }^{65}$. En el procedimiento de determinación de la pena se aprecian antes los efectos de las eximentes incompletas que los del resto de circunstancias ${ }^{66}$. Tras la reforma de 25 de noviembre de 2003, únicamente los requisitos de las eximentes incompletas que falten o concurran y las circunstancias personales de su autor influirán en la primera fase (degradación de la pena en aplicación del art. $68 \mathrm{CP}$ ), mientras que las circunstancias atenuantes y agravantes, dada la actual remisión expresa al art. 66, influirán sobre la segunda. La primera fase consiste en determinar el marco penal inferior en uno o dos grados (se atenderá a los requisitos de las eximentes incompletas que falten y a las circunstancias personales del autor); la segunda fase se refiere a la extensión de la pena dentro del marco penal resultante de la fase anterior (dada la actual remisión expresa al art. 66, se atenderá

61 López López, C., Villa SieIRo, S.V., «Determinación de la pena». Las Consecuencias Jurídicas del Delito, Roca De Agapito, L. (Dir.), Tirant Lo Blanch, Valencia, 2017, p. 98.

62 Santana Vega, D.M., "Artículo 68”, Comentarios al Código Penal; Corcoy Bidasolo, M., Mir Puig, S., Tirant lo Blanch, Valencia, 2015, p. 271 (formato digital).

63 Santana Vega, 2015, p. 271; BorJa Jiménez, 2015, pp. 113-114.

64 Besio Hernández, M., "Valoración y compensación racional de circunstancias atenuantes y agravantes», InDret Penal, 1/2012, p. 5.

65 Boldova Pasamar, 2016, p. 128.

66 Ibidem, pp. 128. 
a las circunstancias atenuantes y agravantes) ${ }^{67}$. "Pero como en el art. 66 se prevén supuestos de agravación y atenuación extraordinaria, éstos podrán entrar también en juego, dando lugar a nuevas reducciones de grado o a elevaciones de grado» ${ }^{68}$. "Por lo tanto, en caso de rebaja de la pena en más de un grado, no habrán de atenderse las reglas del art. 66.1 que operan sobre la extensión de la pena, aunque sí a aquellas reglas que comportan otra modificación del grado de la pena» ${ }^{69}$.

Esta última apreciación de Boldova PASAMAR es muy significativa, pues nos orienta ya hacia un cambio de marco penal posterior al propiciado por la aplicación del art. 68 CP: tras la reducción de la pena en uno o dos grados por aplicación del art. 68, «el grado alcanzado podrá volver a reducirse, elevarse o dividirse en mitades. Si bien, de acuerdo con la regla octava del art. 66.1, cuando se rebaje la pena en dos grados podrá aplicarse en toda su extensión, sin necesidad de dividirla en mitades, con lo cual algunas de las reglas del art. 66 no llegarán a entrar en juego en tales ocasiones ${ }^{70}$.

La desvinculación de las reglas de extensión recogida en el art. 66.1.8. ${ }^{\text {a }} \mathrm{CP}$ deja en un principio abierta la duda de si el Juez mantiene la facultad de subir la pena en grado por el 66.1.4. ${ }^{a}$ tras rebajarla en dos grados por el art. 68. Si se hace una interpretación del 66.1.4. ${ }^{a}$ similar a la última que se acaba de ver respecto del art. 66.1.7. ${ }^{\mathrm{a}}$, en lo que hace a la eximente incompleta se habrá de considerar que, a los efectos de la aplicación del art. 66.1.4. ${ }^{\mathrm{a}} \mathrm{CP}$, y una vez aplicado el art. 68 , no concurre atenuante alguna.

Además, el art. 66.1.4. ${ }^{\mathrm{a}}$ incluye un regla de extensión después de una subida del marco penal, con lo que se dan dos problemas vinculados entre sí, pero diversos:

1. La facultad de subida de grado del art. 66.1.4. ${ }^{\mathrm{a}} \mathrm{CP}$.

2. El sometimiento a las reglas de extensión en el nuevo marco penal.

Si se acepta la subida de grado por aplicación del art. 66.1.4. ${ }^{\mathrm{a}}$ tras una rebaja en más de un grado en virtud del art. $68 \mathrm{CP}$, habrá que considerar que renace en el nuevo marco penal el sometimiento a las reglas de extensión, pues ya no estamos en la pena inferior en más de un grado, sino en la pena superior en un grado a la pena inferior en más de un grado. Es cierto que se ha hecho una rebaja en más de un grado, pero se

67 Ibidem, pp. 130.

68 Ibidem, pp. 130-131.

69 Ibidem, p. 126 (cursivas añadidas).

70 Ibidem, p. 129. El presente trabajo se ciñe al aumento de grado tras la aplicación del art. 68 CP. Para una rebaja de grado en virtud del art. 66, vid. MuÑoz Conde, F., García Arán, M., Derecho Penal. Parte General, $10^{a}$ edición, revisada y puesta al día con la colaboración de García Álvarez, P., Tirant Lo Blanch, Valencia, 2019, p. 516; también, Molina FERNÁNDEZ, 2020, marginal 5532. 
ha dejado atrás. Los jueces o tribunales han recorrido la pena inferior en más de un grado pero están aplicando otra. No se está «aplicando» la pena inferior en más de un grado, que es lo que exige la dicción literal del art. 66.1.8. ${ }^{\mathrm{a}}$, sino la pena superior en grado a una pena inferior en más de un grado.

En consecuencia, si nos encontramos, por ejemplo, con la justificación incompleta de un homicidio doloso con el añadido de la presencia de tres circunstancias agravantes, y si el Juez rebaja la pena en dos grados en virtud del art. $68 \mathrm{CP}$, pueden ocurrir dos cosas:

a) Que el Juez no haga uso de la facultad que le otorga el art. 66.1.4. ${ }^{\text {a }}$ CP. En tal caso, entendemos que es de aplicación el 66.1.3. ${ }^{a}$. Como el 66.1.3. ${ }^{\mathrm{a}}$ incluye una regla de extensión, prima el 66.1.8. ${ }^{\mathrm{a}}$ (tal y como señala el Acuerdo del Tribunal Supremo de 1 de marzo de 2005), y el marco penal será de 2 años y 6 meses a 5 años menos un día de prisión.

b) Que el Juez sí haga uso de la facultad que le otorga el 66.1.4. ${ }^{\mathrm{a}}$. Como el art. 66.1.4. ${ }^{a}$ incluye, como primera operación, un cambio de marco penal, no resulta de aplicación la regla del art. 66.1.8. ${ }^{\mathrm{a}}$, de modo que tenemos que encontrar la pena superior en grado a 2,5-5. Esa pena es 5-7.5. Y habrá que aplicarla en su mitad inferior, tal y como señala el art. 66.1.4. ${ }^{\mathrm{a}}$, pues ya no estamos en la pena inferior en dos grados, sino en la pena superior en grado a la pena inferior en dos grados (quedando así desplazado el art. 66.1.8. ${ }^{\mathrm{a}} \mathrm{CP}$ ). De modo que, en este segundo supuesto, la pena será de 5 años a 6 años y 3 meses de prisión.

\section{Semimputabilidad y multirreincidencia. Conclusiones.}

De acuerdo con lo expuesto en el epígrafe anterior, nada obsta —en principio- a la rebaja en uno o dos grados por la semiimputabilidad (art. $68 \mathrm{CP}$ ) y a la posterior elevación en un grado del marco penal consecuente en virtud de la facultad concedida al Juez por el art. 66.1.5. ${ }^{\mathrm{a}} \mathrm{CP}^{71}$.

La primera cuestión que aquí se suscita es la «qué hacer cuando junto a la multirreincidencia concurra una circunstancia atenuante» ${ }^{72}$; y ello habida cuenta de que, a diferencia del art. 66.1.4. ${ }^{\mathrm{a}}$, el $66.1 .5 .^{\mathrm{a}} \mathrm{CP}$ no incluye una mención expresa a la ausencia de atenuante alguna. Si concurren la agravante de multirreincidencia y una atenuante genérica caben dos soluciones: «La primera consistiría en aplicar primero la regla 5. ${ }^{a}$ del art. 66 subiendo la pena en un grado y aplicar la mitad inferior por concurrir una atenuante (...). En contra de esta solución, hay que

71 Sobre esta circunstancia 5. ${ }^{\mathrm{a}}$ del art. 66.1 CP, véase GIL GIL, LaCRuz LóPEZ, MELENDO PARdos, NúÑEZ FERNÁNDEZ, 2018, p. 251.

72 Ruiz De Erenchun Arteche, 2017, p. 139. 
argüir el carácter facultativo de la subida en grado (...). La otra solución consiste en considerar que, en tal caso, estamos ante el presupuesto fáctico del art. 66.1.7. ${ }^{\text {a }} \mathrm{CP}$, esto es, concurrencia de atenuantes y agravantes, por lo que procedería la valoración y compensación entre ellas y la aplicación, en su caso, de la mitad superior si se entendiera que hay un fundamento cualificado de agravación. Cabría objetar que el legislador debiera haber incluido expresamente la expresión 'no concurriendo ninguna atenuante' ${ }^{73}$.

Mapelli Caffarena alude a un concurso de leyes entre la regla $5 .^{\mathrm{a}}$ (multirreincidencia) y la regla $7 .^{a}$ (compensación racional) del artículo 66.1 CP; concurso que se resolvería en favor de la primera de ellas (66.1.5. ${ }^{\mathrm{a}} \mathrm{CP}$ ), considerada norma especial con respecto a la segunda ${ }^{74}$. "Además, debe tenerse en cuenta que, con carácter general, no pueden compensarse circunstancias ordinarias con las extraordinarias ya que dejaría de ser una compensación 'racional'. Una vez aplicada esta regla acudiríamos a la primera para tener en cuenta la atenuante concurrente» ${ }^{75}$.

El Tribunal Supremo parece dar por buena esta interpretación más estricta, permitiendo la agravación en grado por la multirreincidencia e imponiendo después la pena en la mitad inferior por la concurrencia de una atenuante (STS 532/2018, de 7 de noviembre).

MOLINA FERNÁNDEZ defiende la interpretación contraria en atención a las dudas que plantea en general esta agravación, así como por el propio tenor del art. 66.1.7. ${ }^{\mathrm{a}}$, que, salvo lo ya visto para la eximente incompleta, «no hace excepción alguna al régimen a aplicar cuando concurran atenuantes y agravantes» ${ }^{76}$.

En el mismo sentido, Besio HERnÁNDEZ considera preferible la primacía del art. 66.1.7. ${ }^{\mathrm{a}}$, por cuanto, al menos formalmente, esta regla se refiere explícitamente a la concurrencia de atenuantes y agravantes sin distinción alguna; por el contario, el art. 66.1.5. ${ }^{\mathrm{a}}$ no distingue entre la clase de circunstancias materia de la operación de compensación ${ }^{77}$.

73 Ruiz De Erenchun Arteche, 2017, p. 139.

74 Mapelli CafFarena, 2011, p. 302.

75 Ibidem, p. 302. En relación con la prisión permanente revisable, véase la muy interesante apreciación de FUENTES OSORIO: ¿De qué modo puede tener en cuenta el juez aquellas combinaciones de circunstancias modificativas de la responsabilidad que no generan una bajada de grado, por ejemplo, cuando concurra una sola circunstancia atenuante no cualificada (art. 66.1.1. ${ }^{\mathrm{a}} \mathrm{CP}$ )? "Al no haber un marco penal (...) debería interpretarse, a favor de reo, que siempre se debe bajar un grado», FuENTES OsORIO, J.L., "¿La botella medio llena o medio vacía? La prisión permanente: el modelo vigente y la propuesta de reforma», Revista de Derecho Constitucional Europeo, n 21, 2014, p. 344.

76 Molina FernándeZ, 2020, marginal 5540.

77 Besio HeRNÁNDEZ, 2012, p. 7. 
También LLORCA ORTEGA incluye el art. 66.1.5. ${ }^{\mathrm{a}}$ entre los casos reservados por el legislador para la concurrencia exclusiva de circunstancias agravantes: reglas 3 . $^{\mathrm{a}}, 4{ }^{\mathrm{a}}$ y 5 . $^{\mathrm{a}}$ del art. $66.1 \mathrm{CP}^{78}$.

La FGE (Consulta 2/2004, de 26 de noviembre) considera asimismo que la regla $5 .^{\text {a }}$ solo será aplicable cuando no concurra ninguna circunstancia atenuante.

Un segundo problema planteado por la concurrencia de semiimputabilidad y multirreincidencia es el de la particular referencia que el art. $68 \mathrm{CP}$ hace a las "circunstancias personales» del autor para la rebaja de la pena en uno o en dos grados. Puede causar extrañeza que el art. $68 \mathrm{CP}$ obligue a tomar en cuenta las circunstancias personales del autor cuando el art 66.1 es de obligado cumplimiento y, dentro de su ámbito material de aplicación, es exhaustivo y no deja ni un solo caso fuera de su lista. «Ambos criterios [los del art. 66.1.6. ${ }^{\mathrm{a}} \mathrm{CP}$ ] recogen en una formulación sintética el fundamento de la responsabilidad penal. La gravedad del hecho se refiere tanto a las circunstancias que determinan el desvalor del acto, como el del resultado. Por su parte las circunstancias personales es una clara referencia a los elementos de la culpabilidad ${ }^{79}$.

Habida cuenta de que las circunstancias personales del autor son un elemento central de la determinación judicial de la pena, parece que hay que hacer una predeterminación judicial en el $68 \mathrm{CP}$ antes de pasar a la obligatoria del 66.1. Cabe quizás pensar que la referencia del art. 68 a los elementos que falten o concurran es sinónimo de gravedad del hecho para las eximentes de injusto, mientras que las circunstancias personales del autor encierran una alusión a la intensidad de la alteración que conduce a la semiimputabilidad ${ }^{80}$.

Lo que en todo caso se debe afirmar sin excepciones es que una duplicación contra reo en la valoración de las mismas circunstancias personales vulnera sin más el principio non bis in idem. Hay que advertir a este respec-

78 Llorca Ortega, J., Manual de determinación de la pena, $6^{\mathrm{a}}$ edición, Tirant Lo Blanch, Valencia, 2005, p. 104.

79 Mapelli CafFarena, 2011, p. 303.

80 Para ejemplos concretos, vid. SANTANA Vega, 2015, p. 271 (formato digital): «Las circunstancias personales del autor servirán para valorar la concurrencia o ausencia de los requisitos de las eximentes incompletas (entidad de la disminución de las condiciones volitivas, STS 515/09, 6-5; ponderación de la proporción en la defensa de un guarda de 63 años que dispara frente a la agresión de un joven de 29 años que se introdujo en la finca que guardaba con su vehículo, atacando a aquél con un palo con punta de acero, SSTS 618/05, 12-5)». MAPELLI CAFFARENA considera que, en tanto el proceso de determinación de la pena es una labor continuada, no hay inconveniente en que el órgano judicial vuelva a considerar bajo este doble criterio elementos ya valorados u otros distintos (como, por ejemplo, la pena natural o los perjuicios sufridos durante el proceso), pues los términos abiertos de la redacción son un compromiso con los fines preventivos, lo que invita a una valoración flexible e individualizada, que deberá estar siempre motivada, MAPELLI CAFFARENA, 2011, pp. 303-304. 
to que una rebaja en un grado en virtud de la semiimputabilidad más una subida en grado debida a la multirreincidencia pueden llevar a un marco penal más riguroso que el que hubiera aportado la directa aplicación del art. 66.1.7. ${ }^{\mathrm{a}} \mathrm{CP}$ con un hipotético fundamento cualificado de atenuación.

En atención a lo expuesto hasta el momento, se pueden presentar las siguientes conclusiones:

a) Ha de tomarse como referencia la pena del hecho, que incluye participación y grado de ejecución.

b) Si semiimputabilidad y multirreincidencia concurren a su vez con una causa de justificación incompleta, esta última definirá el límite máximo de la medida de internamiento en tanto determinará el desvalor del hecho.

c) Si semiimputabilidad y multirreincidencia concurren a su vez con una causa incompleta de exclusión de la culpabilidad para la que no se prevé en ningún caso una medida de seguridad, como, por ejemplo, el miedo insuperable, esta última también definirá el límite máximo de la medida de internamiento, pues no se puede hacer de peor condición al semiimputable que al imputable. "En efecto, el hecho de que el acusado estuviera sometido a una situación de terror por la conducta agresora, lesiva e intimidante del coacusado (...) no quiere decir que, a mayores, no pueda concurrir otra eximente referida a una enfermedad mental previa con virtualidad y entidad suficientes para operar autónomamente de la eximente relativa a la situación extraordinaria de temor. Y es que, de seguirse el criterio del Tribunal de instancia, no habría diferencia punitiva alguna en aterrorizar a un sujeto que no padece enfermedad psíquica alguna que a aquel que sí la padece, con lo cual se igualarían punitivamente dos situaciones fácticas claramente dispares, con patente vulneración del principio de justicia», STS 884/2013, de 20 de noviembre.

d) En atención tanto a la dicción literal de, por un lado, los arts. 101, 102 y $103 \mathrm{CP}$, que aluden a la pena si el sujeto hubiera sido declarado responsable, como a la del art. 104, que menciona «la pena prevista por el Código para el delito», la rebaja de pena por la semiimputabilidad no se puede tomar en consideración para la determinación del límite máximo de la medida de internamiento.

Visto todo lo anterior, el aspecto de más interés en este apartado dedicado a la determinación del límite máximo de la medida de seguridad de internamiento para el semiimputable multirreincidente es el siguiente: en la medida en que la multirreincidencia afecta a la culpabilidad del autor, puede resultar incongruente e injusto tomarla en consideración tanto para la determinación de la pena como para la definición del límite máximo de internamiento del semiimputable, pues este último, por sus 
facultades cognitivas o volitivas disminuidas, no debe sufrir el mismo juicio agravatorio automático de su culpabilidad que el que se predica de un imputable pleno ${ }^{81}$.

Respecto de la pena que le hubiera correspondido al inimputable pleno si hubiera sido declarado responsable, MAPELLI CAFFARENA afirma, con contundencia y pleno acierto, que esa pena no solo no existe, sino que no se puede llegar a conocer, "porque para conocer la gravedad de la culpabilidad de una persona es preciso conocer, precisamente, la capacidad que le faltó» ${ }^{82}$.

Resulta llamativo que, a diferencia de lo que ocurre en los artículos 68 y 66.1.6. ${ }^{\mathrm{a}} \mathrm{CP}$, el art. 66.1.5. ${ }^{\mathrm{a}}$ no mencione las circunstancias personales y aluda solamente a la gravedad del hecho. Parece como si las condiciones personales del autor quedasen resueltas todas por su multirreincidencia, en abierta contradicción con el principio de culpabilidad y la fundamentación preventiva de la pena. Del mismo modo que la gravedad del (último) hecho es variable pese a la multirreincidencia, es igualmente obvio que la culpabilidad (por el último hecho) también puede variar pese a la multirreincidencia, pues con esta última no se agota ni mucho menos el juicio sobre las circunstancias personales del autor. La referencia del art. 66.1.5. ${ }^{\mathrm{a}} \mathrm{CP}$ a las condenas precedentes como único factor personal que el Juez ha de considerar en su decisión sobre la subida de la pena en un grado es la huella dactilar que revela la presencia de la culpabilidad por la conducción de vida en la redacción de este precepto, de dudosa constitucionalidad precisamente por la omisión de las circunstancias personales del autor entre los factores que deben influir en la decisión judicial de subida en grado de la pena.

No se debe olvidar que la gravedad del hecho y la culpabilidad del autor determinan la responsabilidad penal por el (último) hecho. Tampoco hay que desatender que la regla $6^{\mathrm{a}}$ del art. $66.1 \mathrm{CP}$ no es aplicable a la decisión de subir la pena en grado, con lo que la valoración flexible e individualizada mencionada con acierto por MAPELLI CAFFARENA ${ }^{83}$ no la alcanza, pues la referencia a las condenas precedentes afecta a varios juicios de culpabilidad por el hecho concluidos y cerrados.

81 Respecto de las relaciones entre reincidencia y culpabilidad atenuada, MIR PUIG, S., La reincidencia en el Código Penal, Bosch, Barcelona, 1974, p. 543; BAcIGALUPo ZAPATER, E., "Principio de culpabilidad e individualización de la pena», El nuevo Código Penal: presupuestos y fundamentos. Libro Homenaje al Prof. Dr. Ángel Torío López, Comares, Granada, 1999, p. 41; MAPElli Caffarena, B., "El insoportable artículo 66 del Código Penal», Estudios penales en Homenaje a Enrique Gimbernat, García ValdÉs, C., VALle Mariscal DE Gante, M., Cuerda Riezu, A., Martínez Escamilla, M., Alcácer Guirao, R., vol. 1, 2008, p. 1166. Un estudio de las relaciones entre injusto, culpabilidad y reincidencia, en PUENTE Rodríguez, L., "Fundamento dogmático de la agravación por reincidencia», Revista Jurídica de la Universidad Autónoma de Madrid, no 26, 2012-II, pp. 193-196.

82 Mapelli CafFarena, 2011, p. 371.

83 Mapelli CafFarena, 2011, pp. 303-304. 


\section{Referencias bibliográficas:}

Alonso Rimo, «Medidas de seguridad y proporcionalidad con el hecho cometido (a propósito de la peligrosa expansión del Derecho penal de la peligrosidad)», Estudios Penales y Criminológicos, n 29, 2009, pp. 107-140.

BACigALUPo ZAPATER, «Principio de culpabilidad e individualización de la pena», El nuevo Código Penal: presupuestos y fundamentos. Libro Homenaje al Prof. Dr. Angel Torío López, Comares, Granada, 1999, pp. 33-48.

Baldó LaVIlla, Estado de necesidad y legítima defensa, Bosch, Barcelona, 1994.

Besio Hernández, Los criterios legales y judiciales de individualización de la pena, Tirant Lo Blanch, Valencia, 2011.

BESIO HERNÁNDEZ, «Valoración y compensación racional de circunstancias atenuantes y agravantes», InDret Penal, 1/2012.

Boldova Pasamar, «Aplicación y determinación de la pena», en Gracia Martín, Boldova Pasamar, Alastuey Dobón, Lecciones de Consecuencias Jurídicas del Delito, $5^{\text {a }}$ edición, Tirant Lo Blanch, Valencia, 2016, pp. 109-143.

BOLEA BARDÓN, «El exceso intensivo en la legítima defensa putativa», Anuario de Derecho Penal y Ciencias Penales, tomo 51, 1998, pp. 613-641.

BorJa JimÉnez, La aplicación de las circunstancias del delito, Tirant Lo Blanch, Valencia, 2015.

CÁmARA ARROYO, «Justicia social y Derecho penal: individualización de la sanción penal por circunstancias socioeconómicas del penado (arts. 66.1.6, 20.7 CP y 7.3 LORRPM)», Anuario de Derecho Penal y Ciencias Penales, $\mathrm{n}^{\circ}$ 68, 2015, pp. 237-275.

CASTElló Nicás, Arbitrio judicial y determinación de la pena en los delitos dolosos (art. 66.1 del Código Penal), Comares, Granada, 2007.

Demetrio Crespo, Prevención general e individualización judicial de la pena, Ediciones Universidad de Salamanca, 1999.

DíEz Ripollés, Derecho penal español. Parte General, $5^{a}$ edición, Tirant Lo Blanch, Valencia, 2020.

FeIJoo SÁnchez, "Individualización de la pena y teoría de la pena proporcional al hecho. El debate europeo sobre los modelos de determinación de la pena», InDret Penal, 1/2007.

Fuentes OsORIO, «¿La botella medio llena o medio vacía? La prisión permanente: el modelo vigente y la propuesta de reforma», Revista de Derecho Constitucional Europeo, $\mathrm{n}^{\circ}$ 21, 2014, pp. 309-345. 
García Albero, «Artículo 104», en Quintero Olivares (Dir.), Comentarios al Código Penal Español. Tomos I y II, $7^{\mathrm{a}}$ edición, Thomson ReutersAranzadi, Cizur Menor, 2016 (formato digital).

García ARÁn, Los criterios de determinación de la pena en el Derecho Español, Universitat de Barcelona, 1982.

GARCía ARÁn, Fundamentos y aplicación de penas y medidas de seguridad en el Código Penal de 1995, Aranzadi, Pamplona, 1997.

Gil Gil, Lacruz López, Melendo Pardos, Núñez Fernández, Consecuencias Jurídicas del Delito. Regulación y datos de la respuesta a la infracción penal en España, UNED, Dykinson, Madrid, 2018.

González Cussac, «Arbitrio judicial y artículo 61.4. a del Código Penal: comentario a la sentencia de 20 de marzo de 1986», Poder Judicial, $\mathrm{n}^{\circ}$ 4, 1986, pp. 141-154.

GRACIA MARTín, «Las medidas de seguridad y reinserción social», en Gracia Martín, Boldova Pasamar, Alastuey Dobón, Lecciones de Consecuencias Jurídicas del Delito, $5^{\text {a }}$ edición, Tirant Lo Blanch, Valencia, 2016, pp. 191-210.

Jiménez Díaz, El exceso intensivo en la legítima defensa, Comares, Granada, 2007.

Jorge Barreiro, Rodríguez Horcajo, "Medidas de seguridad», en Molina Fernández (Coord.), Memento Penal 2021, Lefebvre, Madrid, 2020.

Llorca OrTega, Manual de determinación de la pena, $6^{\text {a }}$ edición, Tirant Lo Blanch, Valencia, 2005.

López López, Villa SieIRo, «Determinación de la pena», en Roca De Agapito (dir.), Las Consecuencias Jurídicas del Delito, Tirant Lo Blanch, Valencia, 2017, pp. 94-103.

Mapelli Caffarena, «El insoportable artículo 66 del Código Penal», en García Valdés, Valle Mariscal De Gante, Cuerda Riezu, Martínez Escamilla, Alcácer Guirao (CoORds.), Estudios penales en Homenaje a Enrique Gimbernat, vol. 1, 2008, pp. 1149-1171.

Mapelli Caffarena, Las Consecuencias Jurídicas del Delito, $5^{\mathrm{a}}$ edición, Thomson Reuters-Civitas, Cizur Menor (Navarra), 2011.

Mapelli Caffarena, Terradillos Basoco, Las Consecuencias Jurídicas del Delito, $3^{\text {a }}$ edición, Civitas, Madrid, 1996.

Mir Puig, La reincidencia en el Código Penal, Bosch, Barcelona, 1974.

Mir Puig, Derecho Penal. Parte General, 10 a edición, 2a reimpresión, en colaboración con Gómez MarTín, VaLIENTE IVÁÑEz, Reppertor, Barcelona, 2016.

Molina Fernández, «Reglas de determinación de la pena», en Molina Fernández (CoOrd.), Memento Penal 2021, Lefebvre, Madrid, 2020. 
Molina Fernández, Mendoza Buergo, «La determinación de la pena. Las instituciones individualizadoras y los sustitutivos de las penas privativas de libertad», en Lascuraín Sánchez (Coord.), Manual de Introducción al Derecho Penal, Boletín Oficial del Estado, Madrid, 2019, pp. 213-251.

Muñoz Conde, García Arán, Derecho Penal. Parte General, $10^{a}$ edición, revisada y puesta al día con la colaboración de GARCÍA ÁlVAREZ, Tirant Lo Blanch, Valencia, 2019.

OBREgón GaRCÍA, «La exclusión social en la determinación de la pena: aplicabilidad de la eximente de alteraciones en la percepción (art. $20.3 \mathrm{CP}$ ) y de otras alternativas», Sistema penal y exclusión social, Benito Sánchez, Gómez Lanz (Dirs.), Thomson Reuters-Aranzadi, Cizur Menor (Navarra), 2020, pp. 83-108.

Puente Rodríguez, «Fundamento dogmático de la agravación por reincidencia», Revista Jurídica de la Universidad Autónoma de Madrid, $\mathrm{N}^{\mathrm{o}}$ 26, 2012-II, pp. 183-202.

RodríGUez Horcajo, "LAS MEDIDAS DE SEGURIDAD», en LaSCURAín SÁNCHEZ (Coord.), Manual de Introducción al Derecho Penal, Boletín Oficial del Estado, Madrid, 2019, pp. 267-287.

Roxin, Derecho Penal. Parte General. Tomo I. Fundamentos. La estructura de la teoría del delito, traducción de la $2^{\mathrm{a}}$ edición alemana (1994) por Luzón Peña, Díaz y García Conlledo, y De Vicente Remesal, Civitas, Madrid, 1997.

Roxin, Strafrecht. Allgemeiner Teil. Band I. Grundlagen. Der Aufbau der Verbrechenslehre, 3. Auflage, C.H. Beck, München, 1997.

Roxin, Strafrecht. Allgemeiner Teil. Band I. Grundlagen. Der Aufbau der Verbrechenslehre, 4. Auflage, C.H. Beck, München, 2006.

Ruiz De Erenchun Arteche, Sistema de Penas, Reglas de Determinación de la Pena y Suspensión de la Ejecución de la Pena, Thomson ReutersAranzadi, Cizur Menor (Navarra), 2017.

Salinero Alonso, Teoría general de las circunstancias modificativas de la responsabilidad criminal y artículo 66 del Código Penal, Comares, Granada, 2000.

SÁnChez Dafauce, «Algunos problemas singulares de la antijuridicidad penal», Nuevo Foro Penal, № 93, 2019, pp. 76-110.

Santana Vega, "Artículo 68», en Corcoy Bidasolo, Mir Puig (Dirs.), Comentarios al Código Penal, Tirant Lo Blanch, Valencia, 2015, pp. 270-271 (formato digital). 
